\title{
PSCAD Simulation Model of D-Statcom for Voltage Sag Improvement
}

\author{
Tamal Roy \\ CSVTU, Bhilai \\ SSCET, Junwani, Bhilai
}

\author{
Mahesh Singh \\ CSVTU, Bhilai \\ SSCET, Junwani, Bhilai
}

\begin{abstract}
This paper deals with the modeling and simulation of Distribution Static Compensator (D-STATCOM) for voltage sag mitigation. The D-STATCOM simulation model consists of 12-pulse inverter, which is connected in shunt with the system. A generalized sinusoidal pulse width modulation (SPWM) technique was developed in the proposed controller for fast control action of the D-STATCOM. Simulations of the D-STATCOM were carried out by using Power System Computer Aided Design (PSCAD) software. Simulation results prove that the D-STATCOM is capable of mitigating voltage sag as well as improving power quality of a distribution system.
\end{abstract}

\section{Keywords}

Power quality, DSTATCOM, SPWM, voltage sag.

\section{INTRODUCTION}

An electric distribution system is a part of an electric system between the bulk power sources and the end users. The bulk power sources are located far away from the load centre and are served to the consumer via distribution system. Modern industries involve the use of non-linear and electronically switched devices in distribution systems. These devices results in power quality problems like voltage sag, voltage swell, flicker, harmonics, voltage imbalance etc. This may cause an impact to the electric supply thus may affect the manufacturing industry and impede the economic development in a country [1].

As a result, development of compensator for improving power quality has become increasing concern for the researchers for the past few decades. Passive compensators like shunt reactor and capacitor are uncontrolled devices and are not able to control the continuous variation of parameters in power distribution system. This leads to the development of new and fast compensator. Just like FACTS devices used for transmission control, custom power devices were developed for distribution control. The custom power devices include compensators like DSTATCOM, DVR, Unified Series Shunt Compensator (USSC), Battery Energy Storage system (BESS) and many other such controllers [2]. Since the introduction of FACTS and custom power concept, devices such as Unified Power Flow Controller(UPFC), Synchronous Static Compensator(STATCOM), Dynamic Voltage Restorer(DVR), solid-state transfer switch and solid-state fault current limiter are developed for improving power quality and reliability of a system[3]-[5]. Investigations have been carried out to study the effectiveness of these devices in power quality mitigation such as sag compensation, harmonics eliminations, unbalance compensation, reactive power compensation, power flow control, power factor correction and flicker reduction[3],[6]-
[8]. These devices have been developed for mitigating specific power quality problems.

Voltage sags is the most important power quality problems faced by many industries and utilities. It contributes more than $80 \%$ of power quality problems that exist in power system. By definition, voltage sag is an rms (root mean square) reduction in the AC voltage at the power frequency, for duration from a half cycle to a few seconds. Voltage sags are not tolerated by sensitive equipments used in modern industrial plants such as process controllers, programmable logic controllers (PLC), adjustable speed drives and robotics [1].

This paper deals with the modeling and simulation of Distribution Static Compensator (D- STATCOM) and it's capability in mitigating Voltage Sag. The modeling and simulation of D- STATCOM is carried out using the PSCAD/EMTDC [9] [10] software.

\section{Basic Configuration and Operation of D-STATCOM}

The D- STATCOM is a three phase shunt connected power electronic device. It is connected near the load at the distribution systems. The major component of D-STATCOM is shown in Fig.1. The basic components of D-STATCOM are 12-pulse voltage source inverters composed of force commutated power semiconductor switches which are connected in shunt with the line through a set of shunt injection transformers.

Since the D- STATCOM employs an inverter to convert the DC link voltage $\mathrm{Vdc}$ on the capacitor to a voltage source of controllable magnitude and phase, it can be treated as voltage- controlled source. Fig. 1 shows the inductance $\mathrm{L}$ and resistance $\mathrm{R}$ which represent the equivalent circuit elements of the step down transformer. Let $V_{s}$ is the distribution system voltage, $\mathrm{V}_{i}$ is the effective output voltage of the DSTATCOM and $\delta$ is the power angle. The reactive power

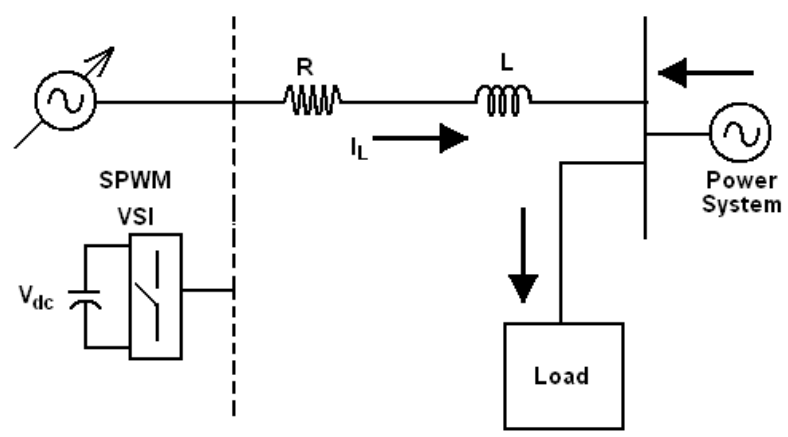

Fig. 1 Basic Building Blocks of D-STATCOM 
output of the D- STATCOM either inductive or capacitive depending on the operating mode of the D- STATCOM. The controller of the D- STATCOM is used to operate the inverter in such a way that the phase angle between the inverter voltage and the line voltage is dynamically adjusted so that the D- STATCOM generates or absorbs the desired reactive power at the point of connection. If $\mathrm{V}_{\mathrm{i}}=\mathrm{V}_{\mathrm{s}}$, then the reactive power is zero and the D-STATCOM does not generate or absorb reactive power. When $\mathrm{V}_{i}$ is greater than $\mathrm{V}_{\mathrm{s}}$, the $\mathrm{D}$ STATCOM shows an inductive reactance connected at its terminal. The current (I) flows through the transformer reactance from the D- STATCOM to the ac system, and the device generates capacitive reactive power. When $\mathrm{Vs}_{\mathrm{s}}$ is greater than $\mathrm{Vi}$, the D- STATCOM shows the system as a capacitive reactance. Then the current flows from the ac system to the D- STATCOM resulting in the device absorbing reactive power.

\section{Simulation Model of D-STATCOM}

The simulation model of the D- STATCOM has been developed using PSCAD/EMTDC software is shown in Fig.2. It consist of 12- pulse inverter arrangement with their primaries connected in series. The first inverter is connected to the system through a $\mathrm{Y}-\mathrm{Y}$ arrangement whereas a $\mathrm{Y}-\Delta$ connection is used for the second inverter. Each inverter operates as a 6-pulse inverter, with the Y- $\Delta$ inverter being delayed by $30^{\circ}$ with respect to the Y-Y inverter. Fig. 3 also shows that the proposed 12- pulse D- STATCOM configured with the GTO's used as a power devices. The GTO's are connected anti parallel with diodes for commutation purposes and charging of the DC capacitor. This GTO switch combination and its capability to act as a rectifier or as an inverter with instantaneous current flows in forward or direction, respectively, constitutes the basic voltage source converter concept.

The DC side of D- STATCOM is connected in parallel to keep the voltage on DC side as low as possible and to improve utilization of DC side capacitor. The two set of three singlephase transformers with a leakage reactance of 0.01 per unit are considered. The first transformer is in Y-Y connection and the second transformer is in $\mathrm{Y}-\Delta$ connection. This is to give a $30^{\circ}$ phase shift between the pulses and to reduce the harmonics generated from the D- STATCOM. Both transformers are stepped down from $22 \mathrm{kV}$ to $4.16 \mathrm{kV}$. The DSTATCOM is connected in shunt with the system. The capacitor plays an important role in the D- STATCOM operation by acting as a DC source to provide reactive power in the system and to regulate the DC voltage. The size of the $\mathrm{DC}$ capacitor considered in this simulation is $3340 \mu \mathrm{F}$.

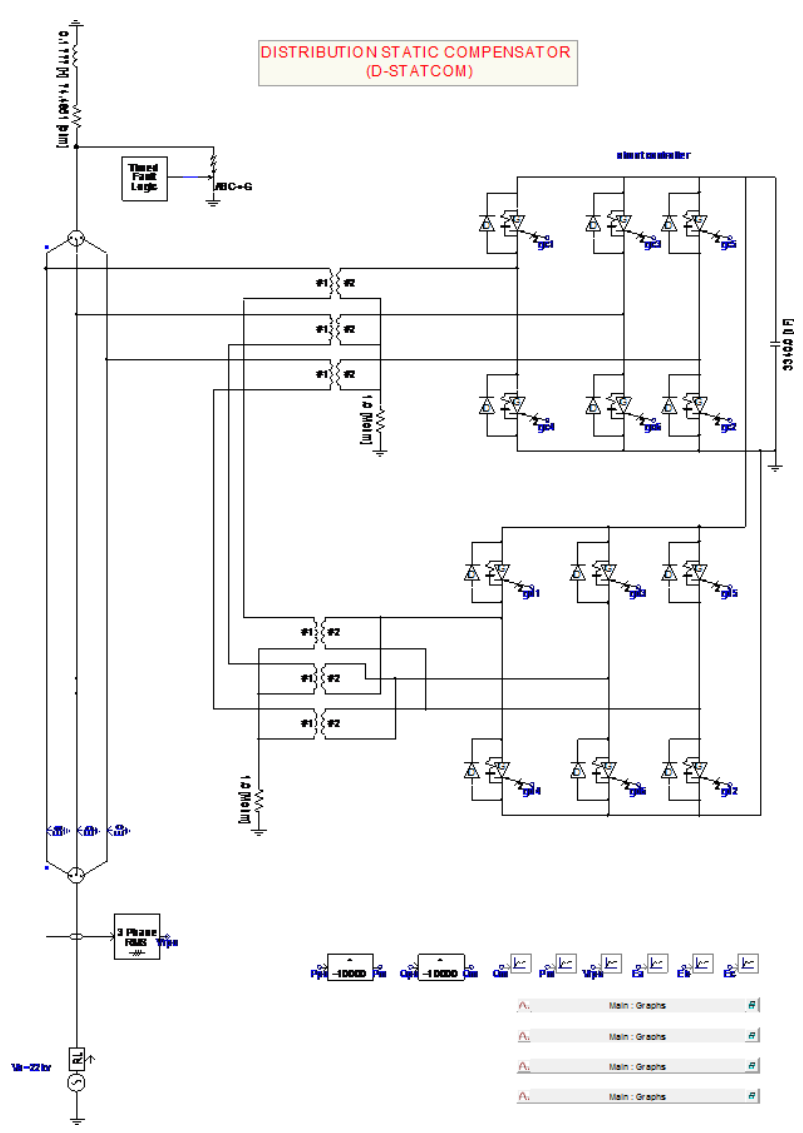

Fig. 2 Simulation Model of D- STATCOM Using 12- Pulse Inverter

\section{Controller Model of D-STATCOM}

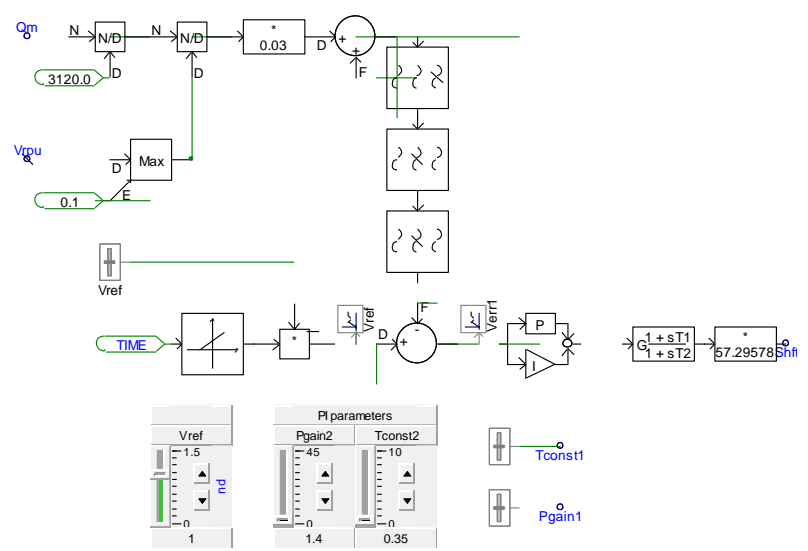

Fig. 3 Reactive Power Control Loop

The control used in this simulation is AC voltage control. This control is divided in to two parts, that is, sinusoidal pulse width modulation (SPWM) and reactive power control. Fig. 3 shows that the PI controller regulates the AC side voltage sourced converter i.e. reactive power into or out of the voltage sourced converter. The output of the PI controller is the angle order, which is used to maintain the phase shift. The reactive power flow from the system is compared to the reference per unit voltage that contributes to a change of the phase shift. The difference of phase shift will provide the necessary reactive power from the $\mathrm{DC}$ capacitor. 


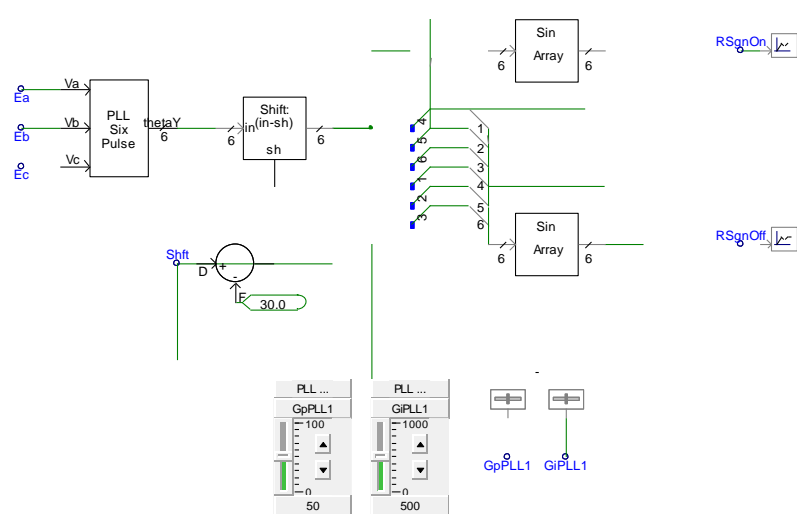

Fig. 4 Generation of Reference Sine Wave

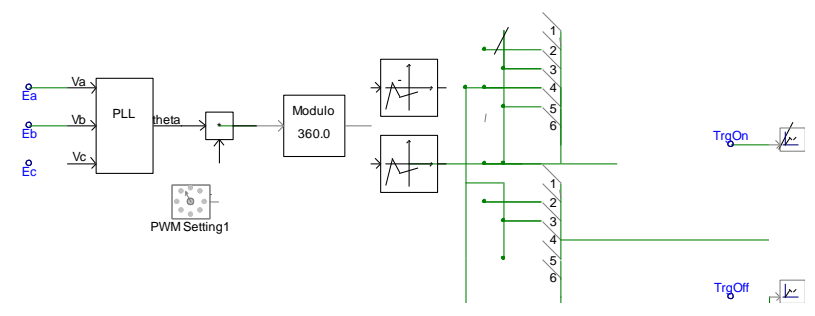

Fig. 5 PWM Carrier Signal

The sinusoidal pulse width technique is used to generate the firing pulse of GTO's so as to mitigate the voltage sag condition. This technique is shown in Fig. 4 and Fig. 5. In this technique, PWM carrier signal are compared with the reference signal. Here the phase locked loop (PLL) plays an important role in synchronizing the switching to the distribution system voltage and lock to the phase at fundamental frequency to generate the PWM triangular carrier signals. When a three phase voltage is fed to the phase locked loop, it generates a ramp signal which is then multiplied with the switching frequency (set at $1.65 \mathrm{kHz}$, which is 33 times the system operating frequency) so as to convert the ramp signal to a triangular signal whose amplitude is fixed between -1 to +1 which is shown in fig. 4 . In Fig. 5, the three phase voltages are applied to the phase locked loop (PLL) to generate reference signal at wanted fundamental frequency.

\section{Simulation Results and Discussion}

The performance of the D- STATCOM model is evaluated by means of simulation techniques using the PSCAD/EMTDC transient simulation program. The D- STATCOM is connected to a $22 \mathrm{kV}$ distribution system with a static load of 5.2 MVA, 0.80 power factor. There are six single- phase transformers with each rated at 1MVA, 22/4.16 kV and a leakage reactance of $0.01 \mathrm{p}$.u connecting the D- STATCOM to the distribution system. Simulations are carried out to illustrate the effectiveness of the D- STATCOM for voltage sag mitigation, as described below.

To illustrate the use of the D- STATCOM to compensate voltage sags, a voltage sag condition is simulated by creating

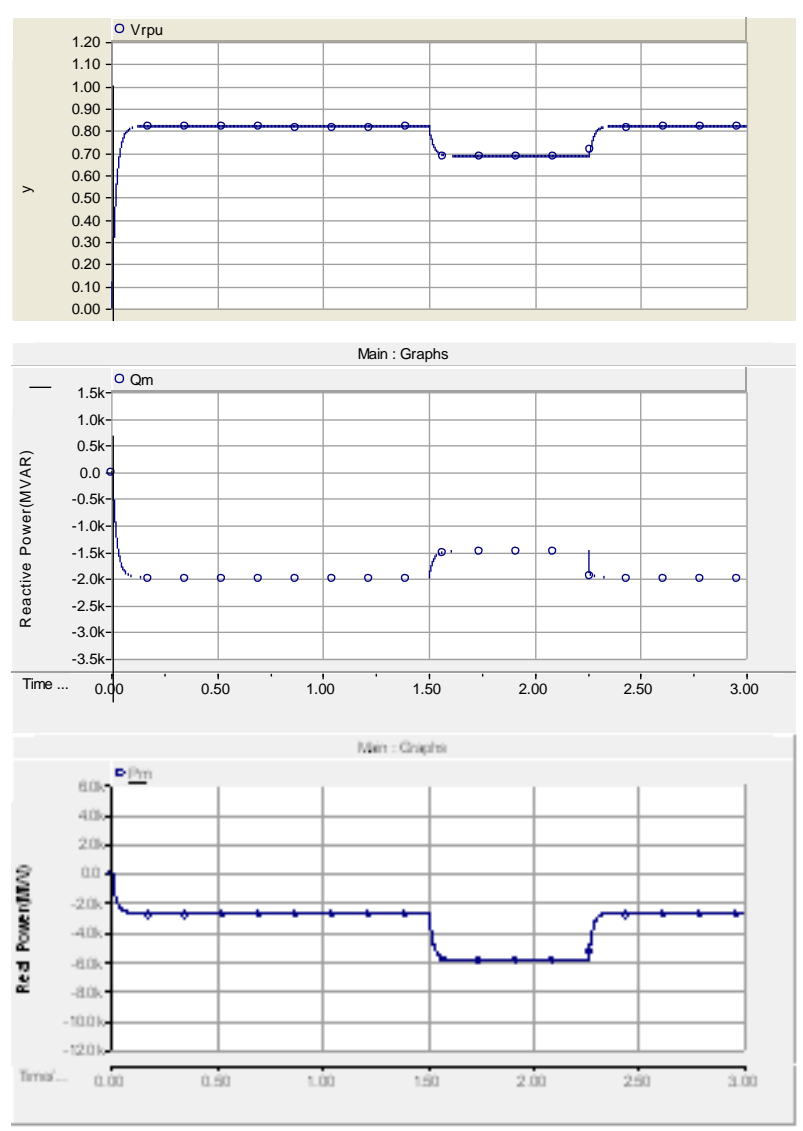

Fig. 6(a) Voltage (pu), Real Power (MW) and Reactive Power (MVAR) under Voltage Sag condition

a balanced three phase to ground fault component available in PSCAD/EMTDC software library. Simulation results showing

the use of D- STATCOM for compensating voltage sags are shown in Fig. 7. in terms of the load voltage in per unit. For the system without D- STATCOM, the load voltage drops from 1.0 p.u to 0.7 p.u as shown in Fig.6(a). This is a voltage sag condition which is due to a three- phase fault created at time $t=1.5 \mathrm{~s}$ for a duration of $0.75 \mathrm{sec}$. For the system with the D- STATCOM connected, the load voltage increases from 0.7 p.u to 0.9 p.u as shown in Fig.6(b). The load voltage almost returns to its rated value due to the voltage sag compensation capability of the D- STATCOM. Fig. 6(b) also shows that the load ripple voltage at the starting and the ending of compensation are due to the charging and discharging of the D- STATCOM capacitor.

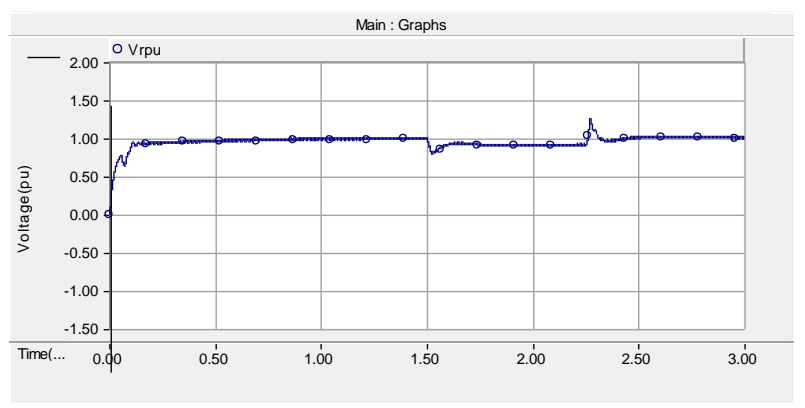




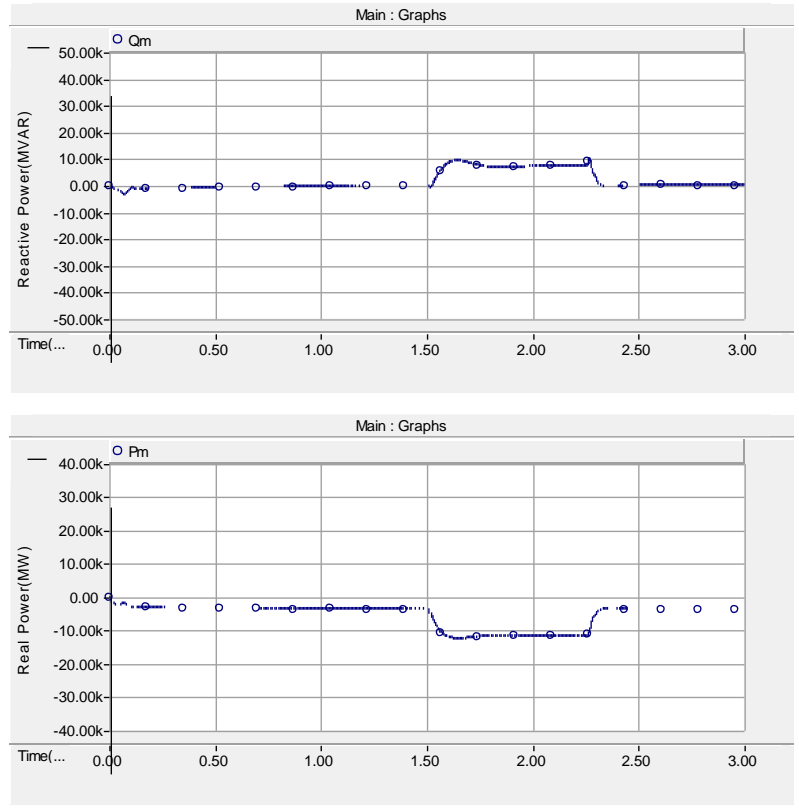

Fig. 7(b) Voltage (pu), Three phase Voltage (kV), Real Power (kW) and Reactive Power using D- STATCOM

\section{CONCLUSION}

The mitigation of voltage sag problems have been investigated by using D- STATCOM. A simulation model of the 12- pulse D- STATCOM has been designed using the PSCAD/EMTDC software and a SPWM- based control scheme has been implemented to control the GTO's of the inverters. The GTO's are connected inversely and parallel to the diodes for commutation purposes and to charge the capacitor. GTO's are used in this simulation because it is easy to control the switch on and off their gates and suitable for designed the D- STATCOM. From the simulation results, it is clear that D- STATCOM works well in mitigating voltage sag caused by three phase to ground fault

\section{REFERENCES}

[1] Hendri Masdi, Norman Mariun and S.M. Bashi, "Design of a Prototype D- STATCOM for voltage sag mitigation" European Journal of Scientific Research, ISSN 1450216X Vol.30 No.1 (2009), pp.112-127 (C) EuroJournals Publishing, Inc. 2009

[2] D.K. TANTI1, BRIJESH SINGH2, DR. M.K. VERMA3, DR. O. N. MEHROTRA "An ANN Based Approach for optimal placement of DSTATCOM for Voltage Sag mitigation" International Journal of Engineering Science and Technology (IJEST)
[3] S. Asha Kiranmai, M.Manjula and A.V.R.S.Sarma "Mitigation of Various Power Quality Problems Using Unified Series Shunt Compensator in PSCAD/EMTDC" 16th NATIONAL POWER SYSTEMS CONFERENCE, 15th-17th DECEMBER, 2010

[4] M. A. Hannan and Azah Mohamed, Member,IEEE "PSCAD/EMTDC Simulation of Unified Series Shunt Compensator for Power Quality Improvement" IEEE TRANSACTIONS ON POWER DELIVERY, VOL. 20, NO. 2, APRIL 2005

[5] Bhim Singh, Kamal Al-Haddad, Senior Member,IEEE, and Ambrish Chandra, Member, IEEE "A Review of Active Filters for Power Quality Improvement" IEEE TRANSACTIONS ON INDUSTRIAL ELECTRONICS, VOL. 46, NO. 5, OCTOBER 1999

[6] M A Hannan and A Mohamed, Senoir Member, IEEE. "Unified Series-Shunt Compensator: Modeling and Simulation" National Power \& Energy Conference (PECon) 2004 Proceedings, KuaIa Lumpur, Malaysia

[7] M.A. Hannan, A. Mohamed, A. Hussain and Majid al Dabbay "Development of the Unified Series-Shunt Compensator for Power Quality Mitigation" American Journal of Applied Sciences 6 (5): 978-986, 2009 ISSN 1546-9239 @ 2009 Science Publications

[8] Olimpo Anaya-Lara and E. Acha, "Modeling and Analysis of Custom Power Systems by PSCAD/EMTDC" IEEE TRANSACTIONS ON POWER DELIVERY, VOL. 17, NO. 1, JANUARY 2002

[9] Manitoba HVDC Research Centre, "PSCAD/EMTDCElectromagnetic transients program including $\mathrm{dc}$ systems", 1994.

[10] A. M. Gole, O. B. Nayak, T. S. Sidhu and M. S. Sachdev, "A graphical electromagnetic simulation laboratory for power system engineering programs" IEEE Trans. Power syst., vol. 11, pp. 599-606, May 1996.

[11] N. Hingorani, "FACTS-Flexible ac transmission systems," in Proc. IEE 5th Int. Conf. AC DC Transmission, London, U.K., 1991, Conf. Pub. 345, pp. $1-7$.

[12] "Introducing custom power," IEEE Spectrum, vol. 32, pp. 41-48, June 1995.

[13] N.G. Hingorani, L. Gyugyi, "Understanding FACTS Concepts and Technology of Flexible AC Transmission Systems", IEEE Press, New York, 2000. 